\title{
International Journal of Medicine
}

\section{Pattern of developmental sex disorders in a tertiary hospital in Sudan}

\author{
Hussein Abdalla M. Ali ${ }^{1}$,Awad Ali M. Alawad ${ }^{2 *}$, Abdelbassit S. Ali ${ }^{3}$, Ahmed Abd Elrahman Abdalla ${ }^{4}$ \\ ${ }^{1}$ Department of Surgery, Faculty of Medicine, Sudan International University, Sudan \\ ${ }^{2}$ Department of Surgery, Faculty of Medicine, University of Medical Sciences and Technology, Sudan \\ ${ }^{3}$ Department of Surgery, Faculty of Medicine, University of Khartoum \\ ${ }^{4}$ Department of Surgery, Faculty of Medicine, University of Gezira \\ *Corresponding author E-mail: awadali82@ hotmail.com
}

\begin{abstract}
Background: Disorders of sex development (DSD) comprise a group of congenital conditions characterized by atypical chromosomal, gonadal, and anatomic sex development. The birth of a child with these disorders considered a medical and psychosocial emergency.

Objective: The aim of this study was to see the prevalence, etiological factors, management, and problems faced in handling these cases. Methods: This is a descriptive retrospective study was conducted at Soba university hospital including all patients with proved DSD over a 6-year period.

Results: One hundred thirty-six cases were seen, of which 40 were included in the study. The median age at presentation was 3 years. The most common cause of XX DSD was congenital adrenal hyperplasia (72.5\%) and that of XY DSD was androgen insensitivity syndrome. Eleven patients $(27.5 \%)$ needed sex reassignment. There was a preference for the male sex.

Conclusion: DSDs are not uncommon in Sudan. Because of lack of awareness and sociocultural reasons cases are referred late. Multidisciplinary teams have to be trained to make services accessible and affordable.
\end{abstract}

Keywords: Children; Disorders of Sex Development; Sudan.

\section{Introduction}

Disorders of sex development (DSD) comprise a group of congenital conditions characterized by atypical chromosomal, gonadal and anatomic sex development (Ahmed \& O'Toole 2012). The percentage of live births in which some aspect of DSD is seen has been estimated at $1 \%-2 \%$, and only $0.1 \%-0.2 \%$ of those infants require corrective surgery at some point (Bertelloni \& Hiort 2010). The rareness of this condition creates a serious challenge for research and patient care. As part of the initial clinical assessment when the presence of DSD is suspected, imaging is performed to localize the gonads, determine the nature and structure of the internal sex organs, and detect any communication with external genital structures (Barbaro et al. 2011).

Gender assignment is a social and legal process not requiring medical or surgical intervention .The role of health care professionals in initial gender assignment is to obtain and help interpret test results concerning the etiology and prognosis of the child's DSD and concerning the status of the child's anatomy and physiology (e.g., hormone production, hormone receptors, gross anatomy), so as to inform the parents' decision about gender assignment. In developing countries, this problem is compounded by limitations of diagnostic and treatment facilities in addition to cultural, social, and religious factors that might affect the management (Gnassingbe et al. 2013).

In this article, we present our experience with DSDs in children seen at Soba university hospital in Sudan over a 6-year period.

\section{Methods}

The records of all patients with a suspected diagnosis of ambiguous genitalia that were referred to Soba University Hospital from January 2006 until January 2012 were reviewed. Those who satisfied the criteria of DSDs as described elsewhere were included in the study. However, those with sex chromosomal DSDs or obvious congenital malformations, such as

Turner syndrome, Klinefelter syndrome, or bladder extrophy were excluded. Information including antenatal history, consanguinity, and similar family history, place of birth, age of first observation, age of presentation, clinical findings, investigations, and management were obtained from the notes. When possible, some missing data were obtained through the telephone. Hormonal measurements were performed locally by direct immunoassay.

Cases were managed by a multidisciplinary team composed of pediatric endocrinologist, pediatric surgeons, urologists, gynecologists, geneticist, pathologist, psychologist, lawyer, and religious leader, in addition to the family.

The collected data were computerized and statistically analyzed using SPSS (Statistical Package for Social Science) version 19. Descriptive statistics were used to quantify the categorical variables. Chi square was calculated to compare between gender role in specialties and factors affecting specialty choices. $P$ value $(<0.05)$ was considered significant difference. The ethical approval for this study was obtained from the ethical committee at the hospital. 


\section{Results}

This study was conducted at Soba University Hospital in a period from January 2006 to January 2012, where 40 patients with DSDs were enrolled, 27 (67.5\%) patients in age group 1- 6 years, two (5 $\%)$ patients were in the age group 6-9 years, and six (15\%) patients in the age group 9-12 years, three $(7.5 \%)$ patients in the age group $12-15$ years, one $(2.5 \%)$ patient aged 16 years and another one $(2.5 \%)$ aged 20 years. Most of the patients, twenty-nine $(72.5 \%)$ were from Khartoum and Gezira states, three $(7.5 \%)$ patients were from Northern State, two patients $(5 \%)$ were from Darfur, White Nile and one patient (2.5\%) from Gedarif, Sennar, Kassala and River Nile states. Concerning consanguinity of parents' patients in this study, five (12.5\%) were second degree relatives and the rest had no relationship. Among these patients of our study only one $(2.5 \%)$ patient had a family history of DSDs. Karyotyping as one of the most useful diagnostic tool for gender identity was done for twenty-eight $(70 \%)$ patients, along with diagnostic laparoscopy, and gonadal biopsies which laparoscopically taken for ten $(25 \%)$ patients and openly for three $(7.5 \%)$ patients. In addition to cystoviginoscopy which was done for thirty-two (80\%) patients.

With history, examination and investigations results, the final diagnoses were reached, which were convincing to the team and the parents and we hope to be satisfactory for the patients themselves at puberty, the diagnoses were as follows: Twenty-nine $(72.5 \%)$ patients were $\mathrm{CAH}$, four $(10 \%)$ patients were true hermaphrodites, four $(10 \%)$ patients were androgen insensitivity syndromes, two $(5 \%)$ patients were female pseudohermaphrodites, and one $(2.5 \%)$ patient male was pseudohermaphrodites (Table1).

Table 1: Distribution of Study Population According To Final Diagnosis

\begin{tabular}{lll}
\hline Diagnosis & Frequency & Percentage \\
\hline True hermaphrodite & 4 & 10 \\
Male psudohermaphrodite & 1 & 2.5 \\
Female psudohermaphrodite & 2 & 5 \\
Congenital adrenal hyperplasia (CAH) & 29 & 72.5 \\
Androgen insensitivity syndrome (AIS) & 4 & 10 \\
Total & 40 & $100 \%$ \\
\hline
\end{tabular}

After reaching the final diagnoses, plans were put for management accordingly, seventeen $(42.5 \%)$ patients were medically treated, twenty-one $(52.5 \%)$ patients were surgically treated, five $(12.5 \%)$ patients were planned for surgery and three patients were surgically and medically treated.

Table 2: Distribution of Study Population According To Medical Management

\begin{tabular}{lll}
\hline Hormone replacement & Frequency & Percentage \\
\hline Cortison & 12 & 30 \\
Testosterone & 1 & 2.5 \\
Estrogen & 0 & 0 \\
Progesterone & 0 & 0 \\
Not done & 27 & 67.5 \\
Total & 40 & $\% 100$ \\
\hline
\end{tabular}

Table 3: Distribution of Study Population According To Surgical Management

\begin{tabular}{lll}
\hline Surgery & Frequency & Percentage \\
\hline Yes & 21 & 52.5 \\
Not done & 14 & 35.0 \\
Planned & 5 & 12.5 \\
Total & 40 & $100 \%$ \\
\hline
\end{tabular}

The surgical procedures which were our concern were as follow out of both planned and operated on patients: Fifteen $(37.5 \%)$ patients were offered reduction clitoroplasty, nine $(22.5 \%)$ patients urogenital mobilization, seven (17.5\%) patients gonadectomy, six $(15 \%)$ patients hypospadius repair and three $(7.5 \%)$ patients underwent vaginoplasty (Figure 1).

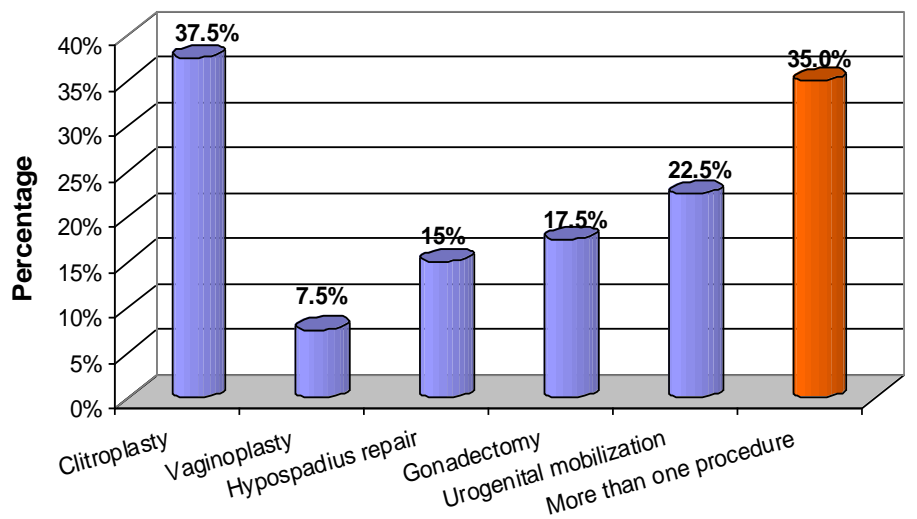

Surgical procedures

Fig. 1: Distribution of Study Population According To Surgical Procedures

These surgical procedures were complicated by postoperative wound infection in two patients $(9.5 \%)$, scarring in three patients $(14.23 \%)$ and loss of tissues in only one patient $(4.76 \%)$ who was circumcised.

The surgical outcome was good with no complications in seven $(33.3 \%)$ patients, satisfactory with complications that mentioned above in six $(28.6 \%)$ patients and eight $(38.1 \%)$ patients with no reported postoperative follow up.

\section{Discussion}

Individuals with congenital discrepancy among the external genitalia, gonadal, and chromosomal sex are classified as having DSDs (Guerra-Junior et al. 2012). Some DSDs present with genital appearance that does not permit prompt gender declaration, and this physical appearance is called ambiguous genitalia, the criteria of which are well discussed elsewhere. In this retrospective study, we have diagnosed 40 cases over a 6-year period, which is the second publication from Sudan (Abdullah et al. 2012). This indicates that this is an important clinical problem in Sudan.

The initial stabilization of infants with DSD requires attention to both medical and psychosocial issues. In Sudan, $70 \%$ of deliveries occur at home and midwives and young doctors are not trained on this issue, and therefore, the gravity of the situation is not well appreciated (Abdullah et al. 2012). Even when referred early, some families refuse to go to doctors because it is considered a stigma or because of financial reasons they cannot travel to these centers. Some cases are left without action, as the etiology is considered to be spiritual and thus not treatable by Western medicine, similar to the experience in some African countries (Gnassingbe et al. 2013). Therefore, many of these children were assigned their sex through guesswork, which has to be done before the naming ceremony, which takes place at the end of the first week of age or no later than 2 weeks. Once the naming ceremony has been done and name and sex announced in public, for socioculture reasons, sex reassignment can create a lot of problems in developing countries (Ahmed \& O'Toole 2012).

The most common cause of XX DSD was congenital adrenal hyperplasia, particularly 21 -hydroxylase deficiency. This is similar to the experience in most parts of the world, particularly in the developing countries, where the consanguinity rate is high (Hiort 2014, Larson et al. 2012, Massanyi et al. 2013).

Since 1899 there were 449 cases of true hermaphrodite recorded in the world literature, $25 \%$ of them were diagnosed after 20 years of age, in South Africa and USA most of true hermaphrodites were $46 \mathrm{XX}$, in Europe 50\% were mosaic, and in Japan all of them were $46 \mathrm{XY}$ (D'Alberton 2010). In comparison to our study group of patients four patients were true hermaphrodites all of them were $46 \mathrm{XX}$ and their age was below 3 years. Androgen insensitivity syndrome occurs in 1 in 20,000 to 1 in 64,000 (Arnhold et al. 2011 ) and in our study in three patients $7.5 \%$. Only one case in our study had a family history of DSD, the patient and her sister 
had CAH. As far as outcome and satisfaction it is very difficult to tell in our study because the real results are determined by the patients themselves, but the satisfaction of the gender assignment can be predicted from their preferred toys and play but finally is determined at puberty, so early surgical correction and gender assignment will only relieve the parents (Gorduza et al. 2010).

Management of these cases needs a multidisciplinary team of pediatric endocrinologist, pediatric surgeons, urologist, laboratory team, geneticists, psychologists, lawyers, and religious leaders. In Sudan, the Sudan Scientific Intersex Society has been established to take care of management of such cases, but such a team is only available in Khartoum. The traveling cost to treating centers can be very expensive and unaffordable for many families. This is perhaps why many of our cases were not able to seek immediate medical help. Training of more staff in all states can help in solving this problem.

\section{Conclusions}

DSDs are not uncommon in Sudan. Many cases are initially missed or referred late by midwives and doctors. A multidisciplinary management team, as mentioned earlier, is only available in the capital; therefore, more trained staff is needed. Sociocultural factors should be considered in sex assignment and timing of surgery. Future follow-up of the cases to see their long-term progress and satisfaction is needed.

\section{References}

[1] Abdullah MA, Saeed U, Abass A, Lubna K, Weam A, Ali AS \& Elmwla IF (2012): Disorders of sex development among Sudanese children: 5-year experience of a pediatric endocrinology clinic. $J$ Pediatr Endocrinol Metab 25, 1065-1072.

[2] Ahmed SF \& O'Toole S (2012): Management of boys and men with disorders of sex development. Curr Opin Endocrinol Diabetes Obes 19, 190-196

[3] Arnhold IJ, Melo K, Costa EM, Danilovic D, Inacio M, Domenice S \& Mendonca BB (2011): 46,XY disorders of sex development (46,XY DSD) due to androgen receptor defects: androgen insensitivity syndrome. Adv Exp Med Biol 707, 59-61.

[4] Barbaro M, Wedell A \& Nordenstrom A (2011): Disorders of sex development. Semin Fetal Neonatal Med 16, 119-127.

[5] Bertelloni S \& Hiort O (2010): Disorders of sex development (DSD). Preface. Sex Dev 4, 191.

[6] D'Alberton F (2010): Disclosing disorders of sex development and opening the doors. Sex Dev 4, 304-309.

[7] Gnassingbe K, Da Silva-Anoma S, Mihleudo-Agbolan K, Anoukoum T, Bignandi K, Akakpo-Numado KG \& Tekou HA (2013): The disorders of sex development and the problems of their management in Togo. Afr J Paediatr Surg 10, 202-203.

[8] Gorduza D, Vidal I, Birraux J, Gay CL, Demede D, Mure PY \& Mouriquand P (2010): The surgical challenges of disorders of sex development (DSD). Arch Esp Urol 63, 495-504.

[9] Guerra-Junior G, Latronico AC, Hiort O \& Rey R (2012): Disorders of sex development and hypogonadism: genetics, mechanism, and therapies. Int J Endocrinol 2012, 820373.

[10]Hiort O (2014): Long-term management of patients with disorders of sex development (DSD). Ann Endocrinol (Paris) 75, 64-66.

[11]Larson A, Nokoff NJ \& Travers S (2012): Disorders of sex development: clinically relevant genes involved in gonadal differentiation. Discov Med 14, 301-309.

[12]Massanyi EZ, Dicarlo HN, Migeon CJ \& Gearhart JP (2013): Review and management of 46, XY disorders of sex development. J Pediatr Urol 9, 368-379. 